\title{
Correction to: A multi-center analysis of adverse events among two thousand, three hundred and seventy two adult patients undergoing adult autologous stem cell therapy for orthopaedic conditions
}

\author{
Christopher J. Centeno ${ }^{1}$ - Hasan Al-Sayegh ${ }^{2}$ - Michael D. Freeman ${ }^{3,7} \cdot$ Jay Smith $^{4}$ • \\ William D. Murrell ${ }^{5} \cdot$ Rostyslav Bubnov $^{6}$
}

Published online: 6 November 2017

(C) SICOT aisbl 2017

Correction to: International Orthopaedics (SICOT)

(2016) 40:1755-1765

https://doi.org/10.1007/s00264-016-3162-y

The published online version contains mistake in Acknowledgment Section. The author name "Steve Gorin, M.D." should have been "Steven Gorin, D.O, M.S.Ed.".

The online version of the original article can be found at https://doi.org/ 10.1007/s00264-016-3162-y.

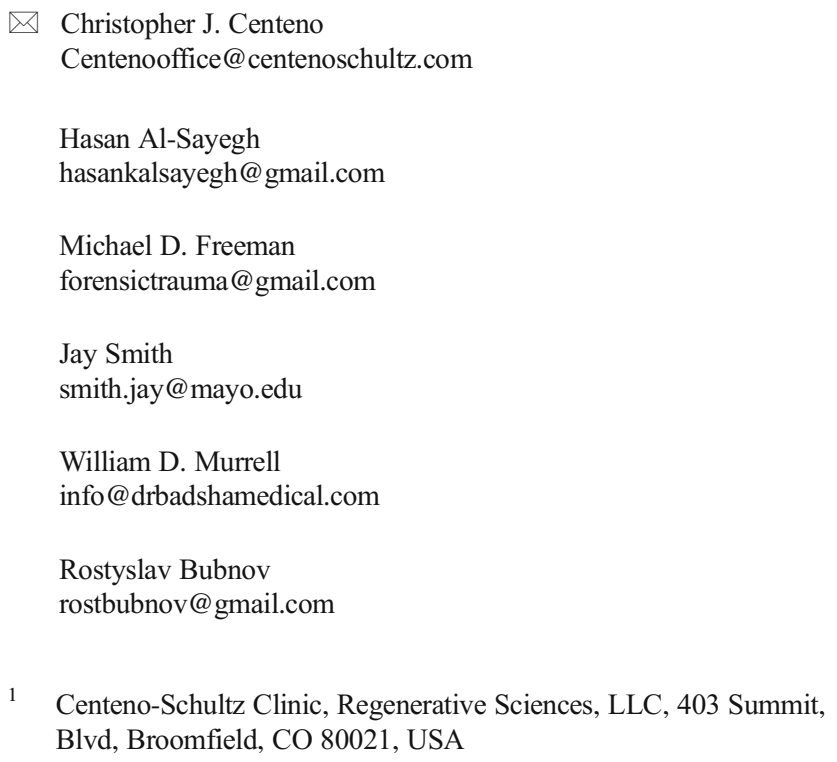

2 Biostatistician at Boston Children's Hospital, 450 Brookline Avenue, D-155E, Boston, MA 02215, USA

3 Department of Psychiatry, Oregon Health and Science University, School of Medicine, Portland, OR, USA

4 Mayo Clinic Rochester, 200 1st St SW, Rochester, MN 55905, USA

5 American Musculoskeletal Wellness Institute, P.C, 6701 Democracy, Boulevard Suite 300, Bethesda, MD 20817, USA

6 The Centre of Ultrasound Diagnostics and Interventional, Sonography, Clinical Hospital "Pheophania" of State Affairs Department, Zabolotny Street, 21, Kyiv 03680, Ukraine

CAPHRI School of Public Health and Primary Care, Maastricht University, Maastricht, the Netherlands 